(C) Masson, Paris, 1979.

Annales de Parasitologie (Paris)

1979 , t. $54, \mathrm{n}^{\circ}$ 5, pp. 533-536.

\title{
A new species of Pbalacrotophora (Dipt. Phoridae) from France
}

\author{
by R. H. L. DISNEY
}

Malham Tarn Field Centre, Settle, North Yorkshire. BD24 9PU, England.

\section{Résumé.}

Une espèce nouvelle de Phalacrotophora (Dipt.-Phoridae) de France.

Un spécimen attribué à Phalacrotophora fasciata (Fallén) par le $\mathrm{D}^{\mathrm{r}} \mathrm{A}$. Delage (1974, Annales de Parasitologie, 49 (4), 495-500) est reconnu comme une espèce nouvelle. Icl est décrit, sous le nom de $P$. delageae, et comparé par $P$. fasciata et $P$. berolinensis Schmitz.

\section{Summary.}

A specimen attributed to Phalacrotophora fasciata (Fallén) by Dr. A. Delage (1974, Annales de Parasitologie 49 (4), 495-500) is recognised as a new species. It is described and named $P$. delageae and compared with $P$. fasciata and $P$. berolinensis Schmitz.

Elsewhere (Disney, 1979) I have pointed out that the drawing of the ovipositor of Phalacrotophora fasciata (Fallén) given by Delage and Lauraire (1974) did not agree with the ovipositor of females collected in England and attributed to this species. Furthermore comparison of females from England with the lectotype female of $P$. fasciata indicated that Dr. Delage's specimen was « a species that is not $P$. fasciata» as it was the English specimens that agreed with the lectotype.

Dr. Delage has now sent me the three specimens she collected in the Jardin des Plantes de Montpellier. Two males, collected 22 July 1969 and 9 July 1970, are indeed $P$. fasciata. It is only the female, collected 11 May 1971, that is not this species. It is a new species which is described below.

Accepté le 27 juin 1979. 


\section{Pbalacrotophora delageae sp. $\mathrm{n}$.}

\section{Female,}

Head: Frons brown but paler, almost orange, ventrally. About as wide as high the height at side, being slightly less than width, but mid-line height (being slightly more). Supra-antennals only $0.06-0.07 \mathrm{~mm}$ long and $0.04-0.05 \mathrm{~mm}$ apart. Antials $0.30-0.31 \mathrm{~mm}$ long and situated only $0.06-0.07 \mathrm{~mm}$ from supraantennals but $0.11-0.12 \mathrm{~mm}$ from antero-laterals, which are near eye margin well above the antials. Antennae yellow with third joint same size and shape at that of $P$. fasciata. Proboscis and palps yellow. The latter with 5-6 short bristles (the longest being just over $0.07 \mathrm{~mm}$ ) in distal quarter.

Thorax: Orange, a little paler on sides. Pubescence black. Some patches of dark pigment between wing base and haltere. Mesopleuron bare. Scutellum with a posterior pair of bristles $(0.33-0,34 \mathrm{~mm}$ long) and an anterior pair of hairs $(0.10$ $0.11 \mathrm{~mm}$ long). Halteres yellow.

Abdomen: Tergites (present on segments 1-4) ,dark with a few, very short, hairs. Belly dusky yellow. Ovipositor (fig. 1) (See also fig. 2 in Delage and Lauraire, 1974) with ventral-apical hairs conspicuously longer and denser than in $P$. fasciata. Fifth segment with glandular structure characteristic of Phalacrotophora females, and likewise third tergite with the usual small circular structure near the front margin on each side.

Legs: Yellow with slightly darker tarsi. Hind femur with four long $(0.15-0.16$ $\mathrm{mm}$ ) hairs beneath basal half. Hind tibia with 7-9 short antero-dorsal setae in basal two thirds, and 8-10 conspicuous, strong postero-dorsals (measuring about $0.13 \mathrm{~mm}$ in length. Hind metatarsus neither swollen or darkened, thus resembling $P$. berolinensis rather than $P$. fasciata.

Wing: (fig. 1, in: Deiage and Lauraire, 1974). Length 2.51-2.52 mm. Costal Index 0.41-0.42. Costal Ratios 4.2:1.6:1. Costal cilia 0.10-0.11 mm long, Veins yellowish, membrane slightly dusky. No hair at base of vein 3 . 3 bristles on axillary ridge.

Material-examined :

Holotype +. Jardin de Plantes, Montpellier, France, 11 May 1971, A. Delage. Deposited in collection of A. Delage.

\section{Affinities.}

Delage and Lauraire (1974) review the European species of Phalacrotophora. $P$. delageae belongs to the subgenus Phalacrotophora by virtue of its bare mesopleuron.

$P$. delageae clearly differs from the female of $P$. spectabilis Schmitz, which has four scutellar bristles, a longer costal index and different costal ratios. $P$. pictofasciata Schmitz is only known in the male sex but differs from $P$. delageae by having four scutellar bristles. Its Costal Index is given by Schmitz (1919) as around 0.44 and he 


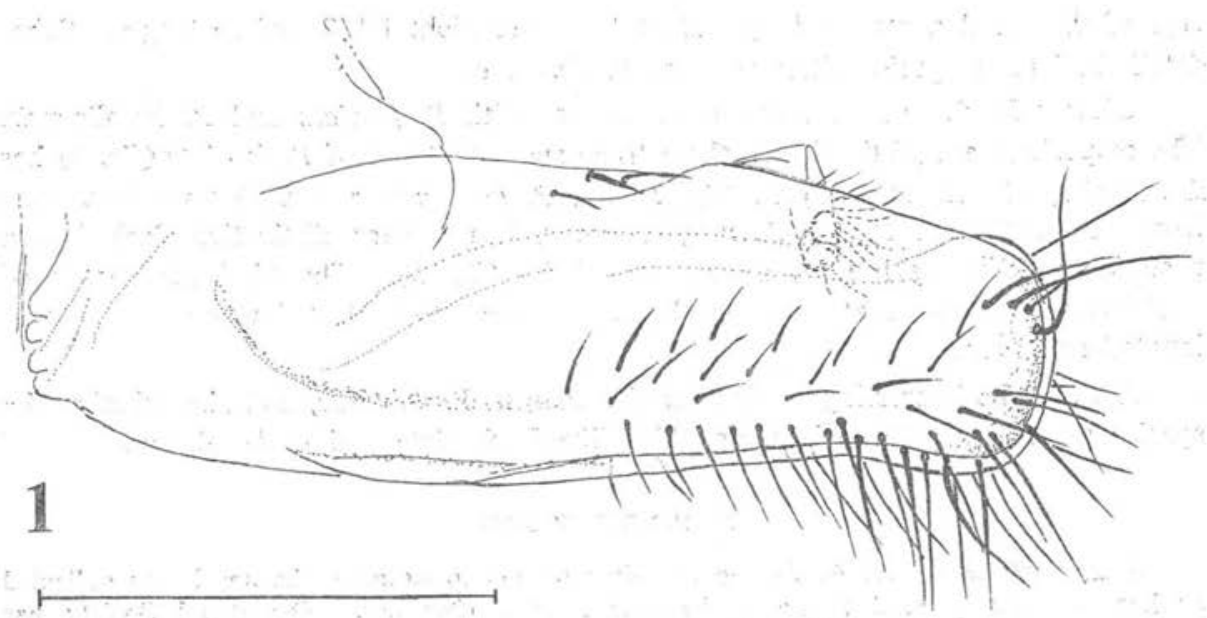

Fig. 1. - Ovipositor of Phalacrotophora delageae n. sp. (Scale line $=0,3 \mathrm{~mm}$ ).

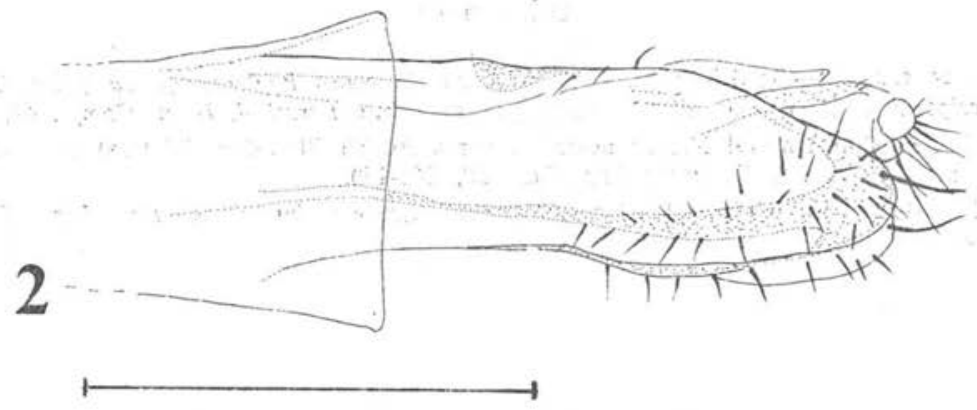

Fig. 2. - Ovipositor of Phalacrotophora fasciata (Scale line $=0.3 \mathrm{~mm}$ ).

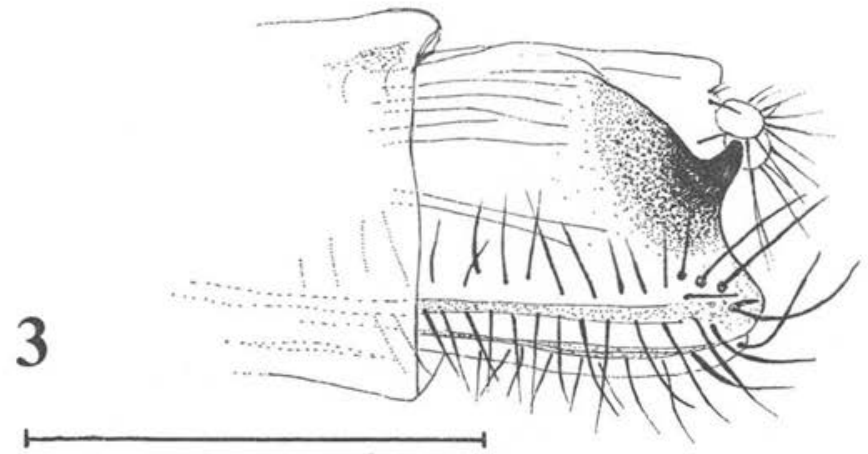

Fig. 3. - Ovipositor of Phalacrotophora berolinensis (Scale line $=0,3 \mathrm{~mm}$ ). 
says of the costal ratios « 1 langer als $2+3$, aber nicht $11 / 2 \mathrm{mal}$ so lang . Other details indicate a species different from $P$. delageae.

Clearly $P$. delageae shows closest affinity with $P$. fasciata and $P$. berolinensis. The ovipositors are, distinctive in these three species. That of $P$. fasciata (fig. 2 ) has short hairs, whereas P. delageae (fig. 1) and P. berolinensis (fig. 3) both have long hairs ventro-distally. $P$. berolinensis, however, has a very distinctive dark brown posterior process (each side) above these hairs (fig. 3). The hind metatarsus of $P$. delageae resembles that of $P$. berolinensis, whereas that of $P$. fasciata is somewhat inflated and darkened.

It would be interesting to discover the male of $P$. delageae, and also whether the species parasitises pupae of coccinellidae like $P$. fasciata and $P$. berolinensis.

\section{ACKNOWLEDGEMENTS}

Il am grateful to Dr. A. Delage for allowing me to examine the specimens collected by her, and am pleased to name the new species after her. The Royal Society has supported my work on Phoridae with two grants.

\section{References}

Delage A., Lauraire M.-Cl., 1974: Mise au point sur le genre Phalacrotophora (Dipt. Phoridae) et description de l'ovipositor d'une femelle parasite. Ann. Parasitol. Hum. Comp., 49, 495-500.

Disney R.H. L. 1979 : Natural history notes on some British Phoridae (Diptera) with comments on a changing picture. Entomologist's Gaz., 30, 141-150.

Schmitz H., 1919: Uber einige Phroden der Oldenbergschen Sammlung. Ent. Ber. Ned. Ent. Ver., 5, 185-196. 